\title{
The Application of Schema Theory to English Reading Teaching in Junior High School
}

\author{
LI Jian-ping, ZANG Li-sha \\ Linyi University, Linyi, China
}

\begin{abstract}
Reading is an effective means to cultivate junior high school students' comprehensive ability of using English and plays an important role in English study. Schema theory is a scientific reading theory advocated by modern teaching, and it regards the reading comprehension as a process that readers' knowledge and skills interact with the information in the reading material. In this paper, a questionnaire is conducted to reveal the fact that students lack schemata in reading and then a proposal that language schema, content schema, and form schema be integrated to activate students' existing schemata in the process of reading is put forward.
\end{abstract}

Keywords: schema theory, English reading teaching, junior high school

\section{Introduction}

If we take learning English as a foreign language, reading is one of the main ways of students' learning the language. Naturally, reading is the key and difficult point in English teaching. However, we realize that many students often fail to do comprehension when asked to read an article. In this situation, in recent years, schema theory has been widely concerned.

In the traditional English reading class in junior high schools, teachers put much emphasis on teaching vocabulary, sentence patterns, and grammar. In the schema theory, these belong to language schema. As a result, they neglect the use of content schema and form schema. Under the pressure of exam-oriented education, students are forced to read word by word, sentence by sentence. As a result, reading comprehension has become a mechanical and passive process. In fact, readers' semantic knowledge and schematic knowledge work interactively together to make them understand the meaning of a text. So in this study the author gives out questionnaires to high school students to find problems in students' reading, and helps English teachers use the three schemata to make English reading teaching more effective.

\section{Schema Theory and Reading}

\section{Definition of Schema}

Immanuel Kant, a German philosopher, first proposed the definition of schema in 1781. In his opinion, concepts are stored in people's memory in an inter-related way but not in a separate way. Then, Bartlett (1932),

LI Jian-ping, lecturer, master, School of Foreign Languages, Linyi University.

ZANG Li-sha, School of Foreign Languages, Linyi University. 
the British psychologist, developed the schema theory. Schema refers to the way and reflection that the brain stores the past experience and the known knowledge. What is more, it is a process that the stored information and the new information interact with each other. Each component of schema forms a slot. When the slot of schema is added by the specific information, schema is formed. The stored knowledge in English learners' mind is of great importance to absorb new knowledge. Therefore, in the process of English learning, activating the known language is just as important as learning new knowledge. This will make the new information easier understood and absorbed, and fuse them to the existing schema to generate new schema. Therefore, the learners can correctly understand and memorize the content of learning.

\section{Types of Schema}

There are three important types of schema: language schema, content schema, and form schema, which have great influence on reading comprehension.

Language schema mainly refers to some basic knowledge of language. Language knowledge covers vocabulary, sentence structure, and grammar. It is the foundation of understanding the reading material.

Content schema refers to the background knowledge about the content (Carrell, 1987). It includes cultural background knowledge, previous experience, related information of a text, etc. Several studies of second-language and reading comprehension indicate that prior cultural experiences are extremely important in comprehending text (Anderson \& Lesgold, 1981; Johnson, 1982).

Form schema is a higher order structure containing knowledge of rhetorical organization structures (Carrell, 1985). It refers to the discourse structure of various genres of articles. Each kind of articles has its specific framework.

\section{Schema Theory and Reading}

According to schema theory, readers are able to understand the sense of reading materials by combining the new information with their existing knowledge and experience. So activating readers' schemata existing in their mind is the nature of reading. American linguist, Johnson (1982) thinks of reading as a bridge between the new and known. As a result, Schema theory can effectively help students to improve the understanding of the article in junior high school.

\section{An Investigation Students' English Reading in Junior High School}

\section{Subjects and Process}

The subjects chosen for this investigation are students in Grade 8 in Qingdao No. 64 Junior High School. The total number of subjects is 400 and they are from eight classes. The students are asked to fill in a questionnaire anonymously.

\section{Questionnaire Design}

The questionnaire (see Appendix) for students is to investigate students' views on English reading, the problems of the students in reading process, and the application of the schema theory in junior high schools.

There are 20 multiple questions. Questions 1-5 are to know students' attitudes towards English reading and language schema. Questions 6-10 are to know the influence of content schema. Questions 11-15 are to know students' difficulties with form schema. Questions 16-20 are designed for the questions about students' English reading methods and strategies. 
By evaluating the questionnaire, the author wishes to find out the problems in reading and give suggestions of applying schema theory in English reading teaching.

\section{Data Collection}

Before delivering the questionnaire papers, the author explains the purpose of the study and some items that were difficult to understand. The participants were encouraged to answer forthrightly. After 15 minutes, 400 questionnaires were collected. And then an analysis was made according to the collected data.

\section{Results and Analysis}

The investigation discusses the attitudes, influence, and difficulties with three schemata, as well as students' reading methods and strategies.

Table 1

Students' Attitudes Towards English Reading and Language Schema

\begin{tabular}{lllllll}
\hline Questions & & 1 & 2 & 3 & 4 & 5 \\
\hline \multirow{3}{*}{$\begin{array}{l}\text { Number of the } \\
\text { answer }\end{array}$} & $\mathrm{A}$ & 146 & 22 & 204 & 122 & 141 \\
& $\mathrm{~B}$ & 210 & 132 & 170 & 102 & 167 \\
& $\mathrm{C}$ & 28 & 242 & 22 & 66 & 92 \\
\hline \multirow{5}{*}{ Rate } & $\mathrm{D}$ & 16 & 4 & 4 & 110 & - \\
& $\mathrm{A}$ & $36.5 \%$ & $5.5 \%$ & $51 \%$ & $30.5 \%$ & $35.25 \%$ \\
& $\mathrm{~B}$ & $52.5 \%$ & $33 \%$ & $42.5 \%$ & $25.5 \%$ & $41.75 \%$ \\
& $\mathrm{C}$ & $7 \%$ & $60.5 \%$ & $5.5 \%$ & $16.5 \%$ & $23 \%$ \\
\hline
\end{tabular}

Analysis: Table 1 indicates that more than $80 \%$ of the students realize that English reading is a significant part in English learning. So, they have a positive attitude towards English reading. However, $60.5 \%$ of the students think their English reading is just so-so, only 16\% of them are satisfied with their reading. Their English reading is not good at all. $30.5 \%$ of the students think the vocabulary is the most difficult part in reading; $25.5 \%$ of them choose grammar; $16.5 \%$ of them choose the structure of the text; and $27.5 \%$ of them think the background knowledge is difficult. And more than $90 \%$ of the students meet new words in the text. Thus, the basic knowledge is the most important part in reading. And most students have difficulties in syntactic structure.

Generally speaking, from the analysis, it can be known that English reading learning can cause attention of the students. But students' reading level is not very good and reading score is not very ideal. There may be two reasons: First, students lack much vocabulary; second, they are unable to distinguish and understand sentences. As is known to all, linguistic schema includes vocabulary, grammar, and sentence structure. So from the result, linguistic schema plays the most significant role in students' English reading. Thus, the first task is to develop students' language schema.

Table 2

Influence of Content Schema

\begin{tabular}{lllllll}
\hline Questions & & 6 & 7 & 8 & 9 & 10 \\
\hline \multirow{3}{*}{ Number of the } & $\mathrm{A}$ & 142 & 66 & 118 & 132 & 189 \\
answer & $\mathrm{B}$ & 168 & 128 & 196 & 155 & 152 \\
& $\mathrm{C}$ & 56 & 184 & 63 & 89 & 54 \\
& $\mathrm{D}$ & 14 & 22 & 24 & 24 & 5 \\
\hline
\end{tabular}




\begin{tabular}{lllllll}
\hline \multirow{4}{*}{ Rate } & A & $35.5 \%$ & $16.5 \%$ & $29.5 \%$ & $33 \%$ & $47.25 \%$ \\
& $\mathrm{~B}$ & $47 \%$ & $32 \%$ & $49 \%$ & $38.75 \%$ & $38 \%$ \\
& $\mathrm{C}$ & $14 \%$ & $46 \%$ & $15.5 \%$ & $22.25 \%$ & $13.5 \%$ \\
\hline
\end{tabular}

Analysis: Table 2 shows that most students like the teacher teaching background knowledge, but more than $50 \%$ of them cannot conjecture the content by the related knowledge. The problem is that students have not stored much background knowledge. This proves that they lack content schema, because content schema includes background knowledge. Content schema stored in readers' brain plays a considerable role in reading comprehension. Nearly $80 \%$ of the students like to read extracurricular English books, so most students are interested in English. However, for most students, reading extracurricular books is just in order to complete teachers' assignment or task rather than to improve their language ability. Thus, lacking of extracurricular reading is also a vital factor to restrict English reading teaching in junior high school. Reading not only depends on the practice in class, but also needs the accumulation in daily life. It is a good way to expand their vocabulary and background knowledge in order to help them understand the read materials better.

Table 3

Students' Difficulties Considering Form Schema

\begin{tabular}{lllllll}
\hline Questions & & 11 & 12 & 13 & 14 & 15 \\
\hline \multirow{3}{*}{$\begin{array}{l}\text { Number of the } \\
\text { answer }\end{array}$} & $\mathrm{A}$ & 136 & 254 & 162 & 18 & 44 \\
& $\mathrm{~B}$ & 144 & 30 & 70 & 212 & 66 \\
& $\mathrm{C}$ & 120 & 82 & 144 & 56 & 178 \\
\multirow{5}{*}{ Rate } & $\mathrm{D}$ & - & 34 & 24 & 114 & 112 \\
& $\mathrm{~A}$ & $34 \%$ & $63.5 \%$ & $40.5 \%$ & $4.5 \%$ & $11 \%$ \\
& $\mathrm{~B}$ & $36 \%$ & $7.5 \%$ & $17.5 \%$ & $53 \%$ & $16.5 \%$ \\
& $\mathrm{C}$ & $30 \%$ & $20.5 \%$ & $36 \%$ & $14 \%$ & $44.5 \%$ \\
\hline
\end{tabular}

Analysis: Table 3 shows that students have some issues in understanding the whole passage. The logical relationship of content and the subject of the paragraph or article account for a large proportion. The reason may be from the question 12. Most students only like reading from beginning to end. This method is mechanical.

More than $70 \%$ of the students are willing to read story and culture. But they know little about exposition and argument, so they think the two are difficult for them to understand. Only when the passages are stories can they read fast. It is known to us all that form schema includes whole structure and types of texts. Understanding the textual structure of different genres is more difficult than basic knowledge and background knowledge.

Table 4

Reading Methods and Reading Strategies

\begin{tabular}{|c|c|c|c|c|c|c|}
\hline Questions & & 16 & 17 & 18 & 19 & 20 \\
\hline \multirow{4}{*}{$\begin{array}{l}\text { Number of the } \\
\text { answer }\end{array}$} & $\mathrm{A}$ & 106 & 101 & 88 & 146 & 84 \\
\hline & B & 66 & 91 & 74 & 154 & 154 \\
\hline & $\mathrm{C}$ & 132 & 66 & 76 & 56 & 90 \\
\hline & D & 96 & 142 & 162 & 44 & 72 \\
\hline \multirow{4}{*}{ Rate } & $\mathrm{A}$ & $26.5 \%$ & $25.25 \%$ & $22 \%$ & $36.5 \%$ & $21 \%$ \\
\hline & B & $16.5 \%$ & $22.75 \%$ & $18.5 \%$ & $38.5 \%$ & $38.5 \%$ \\
\hline & $\mathrm{C}$ & $33 \%$ & $16.5 \%$ & $19 \%$ & $14 \%$ & $22.5 \%$ \\
\hline & D & $24 \%$ & $35.5 \%$ & $40.5 \%$ & $11 \%$ & $18 \%$ \\
\hline
\end{tabular}


Analysis: Table 4 indicates that $26.5 \%$ of the students still use the mechanical method, which they read word by word, sentence by sentence; $33 \%$ of them are used to translating the text into Chinese to help them understand the text. Both of reading methods are time-consuming. Only $16.5 \%$ of them pay attention to the key words. The result shows that it is urgent to help students change the existing approach to reading. $40.5 \%$ of the students agree to guide the reading strategies; $22 \%$ of the students ask for enlarging vocabulary; $18.5 \%$ of them think cultivating the reading interest is important, and $19 \%$ of them think the teachers should supply the related cultural background knowledge of the content. And more than $70 \%$ of them think the reading strategies are helpful. But most of them sometimes or never use the reading strategies.

From the analysis, it is clear to know the importance of learning methods and strategies. On the one hand, students reading methods are time-consuming and mechanical. Good learning methods can improve the efficiency of reading. On the other hand, teachers know that reading strategies are important in reading teaching and students also want some strategies, however, it is a pity that students fail to use these strategies in their reading. The problem of how to use reading strategies is eager to be solved.

The investigation tells us that there are lots of problems of English reading teaching in junior high school, lacking of schemata makes students are unable to have a better understanding of the reading materials. From what mentioned above, the author wishes to give some suggestions, using the knowledge of schema theory, to improve English reading teaching in junior high school.

\section{Suggestions of Applying Schema Theory in Reading Teaching in Junior High School}

Among three types of schema, language schema is the foundation of understanding the text; content schema is the basis of understanding the content; form schema is the ability to call the content. Three schemata work together on English reading. No one can ignore any one of the three. For that reason, it is proposed that schema theory should be widely applied in English reading teaching to cultivate students' reading ability.

\section{Enriching Language Schema}

Language schema is the basis of other two kinds of schema. Vocabulary is the most basic language material, and if readers' vocabulary is big enough, they can know the language better. It can be seen that mastering enough vocabulary is the key to understand the article.

Mastering enough words still cannot fully understand the meaning of the article. The difficult sentences often annoy students. Instead of translating word by word, it is an effective way to understand the sentence by catching the key words and structure.

\section{Establishing Content Schema}

Learning language knowledge is not enough, because English is a language instead of a mere course. If students do not know some cultural background knowledge of English countries, they cannot learn English well.

Cultivating students' interest in extracurricular reading can increase students' reading quantity. Teachers can use objects, pictures, movies, and so on to let students feel the atmosphere of English culture; guide students to carry out a variety of English activities, such as English corner, role plays, debate, etc.

\section{Perfecting Form Schema}

Form schema emphasizes the logical relations of the structure. Once the students master the general 
structure of a certain genre of the article, they will roughly forecast and prove the framework of article so as to improve the overall understanding of the article.

Study in the rhetorical structure of different texts should be strengthened in reading class. Different articles have different genres and different reading materials bear different characteristics which pose different reading requests for teachers. Teachers can cultivate students' interest from the reading materials which they are fond of, and then introduce other complicated types to increase students' understanding of the article.

\section{Conclusion}

The results of the investigation have some implications for English reading teaching in junior high school: (1) Activate students existing schemata in the mind. Before the pre-reading activities, the teacher should guide students to activate the existing schemata or experience to make preparation for understanding the articles; (2) Organically enrich and combine all kinds of schemata in their mind. The understanding of foreign cultures should be strengthened the same as students' language knowledge. For examples, the teacher can introduce some relevant background knowledge about the article according to unit topics. Furthermore, the guidance of discourse consciousness is also essential; and (3) Guide and encourage students to set up the corresponding schema. A good schema is often the combination of textual content and discourse structure; what is more, it is helpful for students to understand and grasp the whole passage.

Generally speaking, it can be known from the discussion that schema is important in students' mind. However, due to the facts that the sample size of the survey is not big enough, only the students are involved while the teachers are not, and the research method only includes questionnaires, further study should be conducted on this issue.

\section{References}

Anderson, R. C., \& Lesgold, A. (1981). Schema-directed process in language comprehension. In Cognitive psychology and instruction. New York: Plenum.

Bartlett, F. C. (1932). Remembering. New York: Cambridge University Press.

Carrell, P. L. (1987). Content and formal schemata in ESL reading. TESOL Quarterly, 21(3), 461-481.

Carrell, P. L., \& Eisterhold, J. (1985). Schema theory and ESL reading pedagogy. TESOL Quarterly, 17(4), 553-573.

Johnson, P. (1982). Effects on reading comprehension of building background knowledge. TESOL Quarterly, 16(4), 503-516.

Ministry of Education. (2011). Curriculum standards of compulsory education. Beijing: Beijing Normal University Press.

Rumelhart, D. E. (1980). Schemata: The building blocks of cognition. In Attention and performance (pp. 573-603). New York, Hillsdale: Erlbaum.

Smith, F. (1971). Reading without nonsense. New York: Teachers College Press.

Widdowson, H. G. (1984). Explorations in applied linguistics 2. Oxford: Oxford University Press.

\section{Appendix: Questionnaire}

1. Do you think English reading class is important?

A. Very important B. Important C. Just so-so D. Not important

2. Are you satisfied with your English reading?

A. Very satisfied B. Satisfied C. Just so-so D. Not satisfied

3. Do you meet many new words in the text?

A. A great many B. Some C. Just so-so D. A few 
4. Which part is most difficult in reading?

A. Vocabulary B. Grammar C. The structure of the text D. Cultural background knowledge

5. What is your syntactic issue?

A. Not sure the structure of long sentences

B. Misunderstand the complex sentences

C. Unable to distinguish syntactic phenomenon

6. Do you like learning cultural background knowledge of English countries?

A. Like very much B. Like C. Just so-so D. Don't like

7. Can you conjecture the content by the title or related knowledge?

A. Always B. Sometimes C. Seldom D. Never

8. Do you like reading some extracurricular English books?

A. Like very much B. Like C. Just so-so D. Don't like

9. What' s your current condition of extracurricular reading?

A. At least read one or two B. Only finish the reading task C. Sometimes D. Never

10. Do you think extracurricular knowledge can help to understand the article?

A. Very helpful B. Helpful C. Little helpful D. Not helpful

11. What is your semantic issue?

A. Confuse the logic relationship between context

B. Can't catch the subject of the paragraph or article

C. Only understand the surface of the article

12. What can you do when you get different reading materials?

A. Read from beginning to end B. Only read interested paragraph

C. Catch the structure of the article D. Don't notice

13. What kind of reading materials are you interested in?

A. Story B. Science and technology C. Culture D. Not interested

14. What kind of articles is difficult for you to understand?

A. Story B. Exposition C. Narrative D. Argument

15. What kind of reading materials do you read faster?

A. News B. Science and technology C. Story D. Not fast

16. What kind of reading methods do you often use?

A. Read word by word B. Catch the key words

C. Translate into Chinese D. Read after the teacher explains

17. What can you do when you meet new words?

A. Consult the dictionary B. Ask the teacher C. Guess meaning D. Ignore

18. What kind of guide does teacher should give?

A. Expand the vocabulary

B. Cultivate the reading interest

C. Supply the related cultural background knowledge of the content

D. Guide the reading strategies 
19. Do you think reading strategies are helpful?

A. Very helpful B. Helpful C. Little helpful D. Not helpful

20. Can you select effective reading strategies to read?

A. Often use B. Sometimes use C. Never use D. Don't know strategies 